Brazilian Journal

of Chemical

Engineering

ISSN 0104-6632

Printed in Brazil

www.abeq.org.br/bjche

Vol. 36, No. 02, pp. 811 - 821, April - June, 2019

dx.doi.org/10.1590/0104-6632.20190362s20180268

\title{
EFFECT OF DISC-BLADE INTERCEPTING ANGLE ON MIXING PERFORMANCE IN A MULTIPHASE STIRRED VESSEL
}

\author{
Huiwen. L ${ }^{1}$, R. Afshar Ghotli2 ${ }^{*}$, R. S. S. Raja Ehsan Shah ${ }^{1}$ and A.A.A. Raman ${ }^{1}$ \\ ${ }^{1}$ University of Malaya, Faculty of Engineering, Department of Chemical Engineering, Kuala Lumpur, Malaysia. \\ E-mail: huiwen_loo@hotmail.com; rshazrin@gmail.com - ORCID: 0000-0001-5147-7667; azizraman@um.edu.my - ORCID: 0000-0001-7586-1903 \\ ${ }^{2}$ University of Malaya, Institute of Ocean and Earth Sciences, Research Management and Innovation Centre, Kuala Lumpur, Malaysia. \\ E-mail: afsharghotli_reza@yahoo.com - ORCID: 0000-0002-3264-9328
}

(Submitted: June 19, 2018 ; Revised: September 9, 2018 ; Accepted: September 17, 2018)

\begin{abstract}
The impeller geometry is a determining factor for mixing efficiency in a stirred vessel. In this study, the effect of disc-blade intercepting angle on power number, just suspended speed and mass transfer coefficient was investigated in a multiphase system under turbulent conditions. The impellers used in this study were fabricated with 3D printing. The interactions between the experimental parameters were analysed using Response Surface Methodology (RSM). The impeller power number was found to have a linear positive relation with disc-blade intercepting angle from $30^{\circ}$ to $90^{\circ}$. Beyond $90^{\circ}$, the impeller power number became lower with increment in the discblade intercepting angle. The results confirmed better suspension efficiency in the angle range of $50^{\circ}$ to $120^{\circ}$ in $5 \mathrm{wt} \%$ solid suspensions. The lowest specific power requirement ( $\mathrm{Ejs})$ at just suspension condition was observed in the angle range of $30^{\circ}$ to $80^{\circ}$. The highest mass transfer coefficient was obtained for the impellers with disc-blade intercepting angle in the middle range. Two models were established on power number and mass transfer coefficient for various disc-blade intercepting angles. The study confirmed that the hydrodynamic and mass transfer performance of disc blade impellers could be maximized by changing the disc-blade intercepting angle for a selected system.

Keywords: Disc-blade intercepting angle; Power number; Just suspended speed; Mass transfer coefficient; RSM.
\end{abstract}

\section{INTRODUCTION}

Mixing operations are one of the important industrial processes for homogenization, suspension, dispersion and heat transfer intensification applications (Zlokarnik, 2008). Mechanical agitation using a stirred vessel and impellers are commonly employed in chemical, biotechnological and food processing industries. Many studies have shown the significance of impeller geometry in mixing quality. Therefore, impeller geometry has been broadly studied to optimize mixing performance.

Since the first inception of the Rushton turbine in 1946, many designs of impellers other than the standard six-flat-blade Rushton turbine have been developed. Many works have been accomplished on impeller design and the effect of various geometries such as blade number, blade thickness, blade width, pitch angle, blade twist, blade curvature angle, and blade shape on impeller efficiencies. The requirement of mixing quality varies over different applications. Mixing quality can be characterised by various parameters such as power consumption, just suspended speed, and mass transfer coefficient. The knowledge of these parameters is essential due to direct impact on the product quality, process productivity and cost.

Power number is one of the most universal design specifications in the mixing operation which is used to estimate power consumption of various impeller designs. Generally, impellers with low power number $\left(\mathrm{N}_{\mathrm{p}}=0.1-0.5\right)$ create moderate flow while impellers with high power number $\left(\mathrm{N}_{\mathrm{p}}>3\right)$ generate high turbulence

\footnotetext{
* Corresponding author: R. Afshar Ghotli - E-mail: afsharghotli_reza@yahoo.com
} 
flow (Kumaresan and Joshi, 2006). Several attempts can be found through the literature to determine the power number for different impeller deigns. Typically, the well-known radial flow Rushton turbine has a power number ranging from about 4 to 6 (Bates et al., 1963; Bujalski et al., 1987; Nienow and Miles, 1971; Rushton et al., 1950; Rutherford et al., 1996). Power numbers for the Pitched-blade axial flow turbines were found in the range of 1.5 to 3.0 (Bujalski et al., 1987; Jahoda et al., 2007; Karcz and Major, 1998; Khare and Niranjan, 1999; Nienow, 1997; Pacek et al., 1999; Patwardhan and Joshi, 1999; Rewatkar et al., 1990; Wu et al., 2001). The $\mathrm{N}_{\mathrm{p}}$ values for other impeller designs like curved blade turbines and parabolic blade designs were obtained in the range of 2.8 to 3.8 (Afshar Ghotli et al., 2013; Chen and Chen, 2000; Forrester et al., 1998; Khare and Niranjan, 1999; Mhetras et al., 1994; Warmoeskerken and Smith, 1989) and 2.12 to 2.3, respectively (Khare and Niranjan, 1999; Vasconcelos et al., 1999). Kumaresan and Joshi (2006) investigated a PBTD and their results showed an increase in the power number with increasing number of blades (Kumaresan and Joshi, 2006). Dimensions of the blade, for instance blade thickness, had a significant influence on power number of RT (Bujalski et al., 1987; Rutherford et al., 1996), but it has no effect on the power number for a 4PBT impeller (Chapple et al., 2002). In addition, an increment in W/D ratio also increases impeller power number (Kumaresan and Joshi, 2006). Increasing blade width of an impeller by $60 \%$ increases the power consumption by approximately $25 \%$ (Rewatkar et al., 1991). An iincrease in blade angle of a PBT increases the power number (Patwardhan and Joshi, 1999). However, the presence of blade twist in a PBT reduces the power number (Kumaresan and Joshi, 2006). Patwardhan and Joshi (1999) also found that the power number decreased with na increase in blade twist. Blade curvature angle also has a significant effect on the impeller's power number (Afshar Ghotli et al., 2013). A more recent study by Sutudehnezhad and Zadghaffari (2017) also pointed out that curved blade impeller could enhance the mixing efficiency up to $61.3 \%$ in comparison with Rushton turbine. Vanconcelos et al. (2000) tested the performance of a retrofitted 6-blade Rushton turbines and found that blade streamlining lowered the impeller's power number and caused less un-gassed power reduction.A study by Cooke and Heggs (2005) on streamlined- blade design of hollow blade impeller also confirmed better ability of this impeller to disperse gas without significant power loss compared to RT.

The importance of just suspended speed or critical impeller speed, $\mathrm{N}_{\mathrm{js}}$ has been recognised by pioneering works from Zwietering (1958) and Nienow (1968). Zwietering's correlation is the most widely used correlation for $\mathrm{N}_{\mathrm{j} s}$;
$\mathrm{N}_{\mathrm{js}}=\frac{\mathrm{S} v^{0.1} \mathrm{~d}_{\mathrm{p}}^{0.2} \mathrm{X}^{0.13}\left(\frac{\mathrm{g} \Delta \rho}{\rho_{\mathrm{L}}}\right)^{0.45}}{\mathrm{D}^{0.85}}$

where $\mathrm{S}$ is a constant dependent on impeller type, impeller diameter, and off-bottom clearance, $v$ is the kinematic viscosity $\left(\mathrm{m}^{2} / \mathrm{s}\right), \mathrm{g}$ is the gravitational acceleration constant $\left(\mathrm{m} / \mathrm{s}^{2}\right), \mathrm{D}$ is the impeller diameter $(\mathrm{m})$, and $\mathrm{X}$ is the solid concentration. $\rho_{\mathrm{S}}$ and $\rho_{\mathrm{L}}$ represent the densities of the solid and liquid phases, respectively $\left(\mathrm{kg} / \mathrm{m}^{3}\right)$ and $\mathrm{dp}$ the particle diameter $(\mathrm{m})$.

At the complete suspension condition, all surfaces of the solids are in contact with the fluid, thus enabling maximum available surface area for chemical reactions (Kasat and Pandit, 2005). Wu et al. (2001) reported reduction in $\mathrm{N}_{\text {is }}$ for $\mathrm{PBT}$ and $\mathrm{RT}$ with an increase in the number of blades. Moreover, an increase in blade angle of PBT reduced $\mathrm{N}_{\mathrm{is}}$ (Wu et al., 2001). Jirout and Rieger (2011) compared the standard three blade turbine with profiled blades impellers and found that a 3PBT with diagonally folded blades had the lowest $\mathrm{N}_{\mathrm{js}}$ and $\mathrm{P}_{\mathrm{j} s}$, compared to the standard $45^{\circ} 3 \mathrm{PBT}$ and cylindrical 3PBT (Jirout and Rieger, 2011).

In agitation systems involving gas and liquid, the mass transfer between both phases is often the ratecontrolling step and it directly affects the performance of the process. $\mathrm{k}_{\mathrm{L}} \mathrm{a}$ is also concerned in bioreactor applications to ensure sufficient oxygen and nutrient transfer for cell cultivation or aerobic fermentation (Schaepe et al., 2013). Some researchers have reported the dependency of $\mathrm{k}_{\mathrm{L}}$ a on impeller type, impeller speed and gas flow rate (Arjunwadkar et al., 1998). Chen and Chen (1999) studied the mass transfer in an airwater system for various single-twin impeller systems, including Rushton impellers, pitched-blade impellers, concave-blade impellers and comb-blade impellers. Their results showed slightly better mass transfer performance by using concave-blade and combblade impellers (Chen and Chen, 1999). This is also supported by a study from Suhaili et al. (2010), which highlighted that the use of a dual concave blade disc turbine increased the oxygen transfer rate by about 5-50 \% and 18-65\% compared to the conventional RTRT system in Newtonian and non-Newtonian systems, respectively.

Although extensive studies have been accomplished on impeller design in stirred vessels, none of the studies have reported the variation in the angle where the impeller blades intercept with the central disc. In view of this, the present research aims to study the effect of disc-blade intercepting angle on mixing performance through power, just suspended speed and mass transfer coefficient measurements. This research should lay a foundation for a systematic approach towards impeller design development by categorical optimization. 
Response Surface Methodology (RSM) is a statistical tool used in designing experiments and analysing relationships between interacting parameters and their significance. It is a useful statistical technique to evaluate complex variable processes (Jeong et al., 2009). Using the RSM method to analyse the interaction between parameters in mixing experiments is still relatively recent (Afshar Ghotli et al., 2013; Afshar Ghotli et al., 2016; Asgharzadehahmadi et al., 2016) although it is common in other fields of research. In this study, RSM was used to represent the effects of disc-blade intercepting angle and Reynolds number on power number, and the effects of disc-blade intercepting angle and superficial gas velocity on the mass transfer coefficient.

\section{METHODOLOGY}

\section{Set-up and Materials}

The experiments were performed in a flat-bottom cylindrical transparent Perspex vessel with a diameter of $0.2 \mathrm{~m}(\mathrm{~T})$. The tank was equipped with four full baffles having width of $B=T / 10$. A single test impeller was mounted on a central shaft with the impeller clearance fixed at $\mathrm{C}=\mathrm{T} / 3$. The ratio of impeller diameter to tank diameter (D/T) was $1 / 3$. Standard stirred vessel dimension ratios were employed to enable reasonable comparison with other studies (Kumaresan et al., 2005). The liquid height was kept equal to the tank diameter $(\mathrm{H}=\mathrm{T})$. A ring sparger with an outer diameter of 0.8 times of the impeller diameter was used. The sparger had a total of 15 holes at its bottom with equivalent hole diameter of $1 \mathrm{~mm}$. Sparger clearance was maintained at $\mathrm{C}=\mathrm{T} / 6$ and located below the impeller. The dimension and position of the sparger were chosen following the recommendation of previous work (Rewatkar et al., 1993). A Heidolph overhead stirrer was used; its speed can be varied in the range of 50 to $2000 \mathrm{rpm}$ and measures torque with accuracy to $0.001 \mathrm{Nm}$. A schematic diagram of the experimental set-up is shown in Figure. 1. Distilled water was used as the liquid phase in all the experiments. $5 \% \mathrm{wt}$ ballotini particles (spherical glass particles) with particle size of $355-550 \mu \mathrm{m}$ and 2500 $\mathrm{kg} / \mathrm{m}^{3}$ density were used as the solids. Compressed air was used as the gas phase and nitrogen gas was used
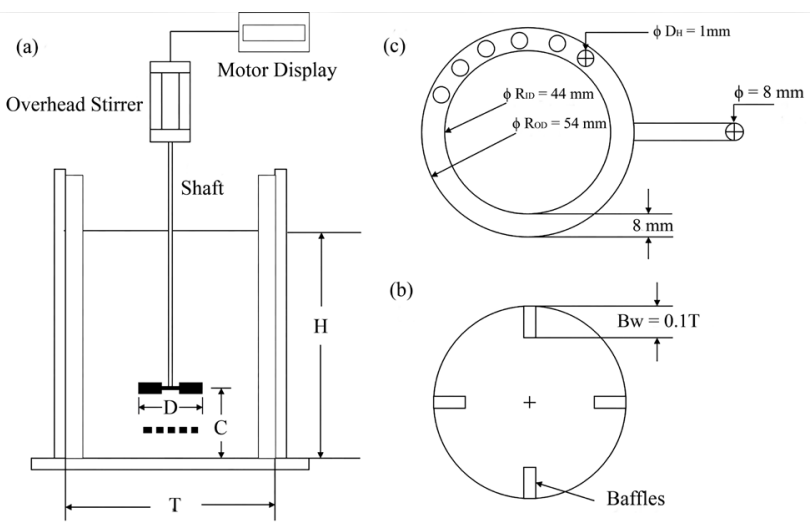

Figure 1. Schematic diagram of the experimental set up. (a) Stirred tank (b) Top view of stirred tank (c) Sparger design.

Table 1. Geometrical dimensions of the stirred vessel.

\begin{tabular}{cc}
\hline Parameter & Dimension \\
\hline Vessel Diameter, T & $0.2 \mathrm{~m}$ \\
Number of baffles & 4 \\
Baffle Width & $\mathrm{T} / 10$ \\
Impeller Diameter, D & $\mathrm{T} / 3$ \\
Impeller Clearance, C & $\mathrm{T} / 3$ \\
Sparger Diameter, Ds & $0.8 \mathrm{D}$ \\
Sparger Clearance, Cs & $\mathrm{T} / 6$ \\
Liquid Height, H & $\mathrm{T}$ \\
\hline
\end{tabular}

as the purging gas for deoxygenation purposes. The superficial gas velocities were varied in the range of $0.001 \mathrm{~m} / \mathrm{s}$ to $0.003 \mathrm{~m} / \mathrm{s}$.

\section{Impeller Design with 3D Printing}

The availability of 3D printing technology has allowed rapid prototyping of many engineering designs. In this work, 3D printing was employed to fabricate the impellers. The usage of a 3D-printer enabled the fabrication process of impellers to be cost effective and time saving. An UP Plus 2 3D-Printer was used with ABS (Acrylonitrile-Butadiene-Styrene) filament as the material. The ABS material was chosen as it is a stronger and more impact-resistant plastic, hence better suited for mechanical parts like impellers. Thirteen 3D-printed impellers with different discblade intercepting angles were fabricated. The details of the impeller designs are shown in Figure. 2. All
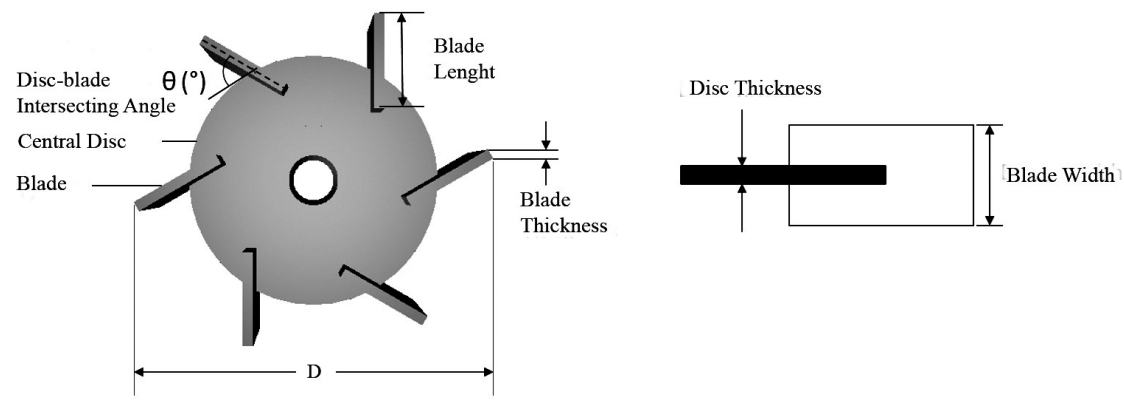

Figure 2. Impeller geometry. 
the impellers were fabricated with the diameter of 67 $\mathrm{mm}$, the disc thickness of $2 \mathrm{~mm}$, the blade thickness of $14 \mathrm{~mm}$ and blade length of $18 \mathrm{~mm}$. The disk blade intercepting angles were in a range of $30^{\circ}$ to $150^{\circ}$.

\section{Mixing Characteristics Analysis}

Power Measurement

Power was calculated from the impeller shaft speed, N (rps) and torque, $\tau$ (N.m):

$P=2 \pi N \tau$

Torque values were taken from the reading measured by the Heidolph stirrer at each specific stirring speed, $\mathrm{N}$. The power numbers of impellers were computed using the following expression:

$\mathrm{N}_{\mathrm{P}}=\frac{\mathrm{P}}{\rho \mathrm{N}^{3} \mathrm{D}^{5}}$

where $P$ represents power input (W) and $\rho$ is the density of the liquid $\left(\mathrm{kg} / \mathrm{m}^{3}\right)$ and $\mathrm{D}$ is the impeller diameter $(\mathrm{m}) . \mathrm{N}_{\mathrm{p}}$ can be represented as a function of Reynolds number, $\mathrm{N}_{\mathrm{p}}=\mathrm{f}(\mathrm{Re})$ in geometrically-similar systems. Impeller Reynolds number is obtained with the subsequent equation:

$\operatorname{Re}=\frac{\mathrm{ND}^{2} \rho}{\mu}$

Plots of power number versus Reynolds number were presented for all impeller designs in the turbulent region.

\section{Just suspended speed}

Just suspended speed, $\mathrm{N}_{\mathrm{js}}$ was determined in accordance with Zwietering's criterion (Zwietering, 1958) by visual observation, which was the condition where no solid remained stagnant at the bottom of the tank for more than 1 or 2 seconds. By following Zwietering's rule, $\mathrm{N}_{\mathrm{js}}$ can be consistently judged within an accuracy of approximately $\pm 5 \%$ in all experiments by the same observer. In this study, observation was done by illuminating the tank with light from beneath and an inclined mirror to aid observation of the tank bottom. Once the just suspended condition was achieved, the speed of the stirrer was recorded.

\section{Mass Transfer Coefficient}

The volumetric gas-liquid mass transfer coefficient $\left(\mathrm{k}_{\mathrm{L}} \mathrm{a}\right)$ was measured with the dynamic gassing-out method (Kapic and Heindel, 2006; Van't Riet, 1979). In the beginning of each experiment, the system is sparged with nitrogen gas to deoxygenate the water. The Orion Star A323 (Thermo Scientific, USA) online dissolved oxygen meter was used to measure the increment of dissolved oxygen level over time once the compressed air was sparged into the system. The concentration of dissolved oxygen was recorded every 3 seconds until the liquid was saturated by oxygen. Superficial gas velocity is defined as the gas flow rate divided by the mixing tank cross-sectional area.

The overall volumetric gas-liquid mass transfer coefficient was calculated using the following equation:

$$
\mathrm{k}_{\mathrm{L}} \mathrm{a} \cdot \mathrm{V}\left(\mathrm{C}^{*}-\mathrm{C}_{\mathrm{t}}\right)=\mathrm{V} \cdot \frac{\mathrm{dC_{t }}}{\mathrm{dt}}
$$

Integration of equation (5) gives;

$\ln \left(\frac{\mathrm{C}^{*}-\mathrm{C}_{0}}{\mathrm{C}^{*}-\mathrm{C}_{\mathrm{t}}}\right)=\mathrm{k}_{\mathrm{L}}$ a.t

Here $\mathrm{C}^{*}$ is the saturated dissolved oxygen concentration $(\mathrm{mg} / \mathrm{l}), \mathrm{C}_{0}$ is the initial concentration (mg/l) while $\mathrm{C}_{\mathrm{t}}$ is the dissolved oxygen concentration at time $\mathrm{t}$ in the reactor $(\mathrm{mg} / \mathrm{l}) . \mathrm{k}_{\mathrm{L}}$ a was obtained from the slope of a straight line by plotting the left-hand side of equation (6) against time.

\section{Statistical Analysis}

Response surface methodology (RSM) is a collection of mathematical and statistical techniques for modelling, analysis and determination of regression model equations and operating conditions through quantitative data of appropriate experiments. The RSM with central composite design (CCD) approach was used in this study to outline the experimental run sets to analyse the effect of disc-blade intercepting angle and Reynolds number on power number and superficial gas velocity and disc-blade intercepting angle on mass transfer coefficient.

The independent experimental variables consisting of the disc-blade intercepting angle, $X_{1}$, Reynolds number, $\mathrm{X}_{2}$, superficial gas velocity, $\mathrm{X}_{3}$ and their coded levels for the CCD are presented in Table 2. The responses were power number, $\mathrm{Y}_{1}$ and mass transfer coefficient, $\mathrm{Y}_{2}$.

The number of experiments needed for the CCD method was computed with equation (7), consisting of $2^{\text {n }}$ factorial runs with $2 \mathrm{n}$ fixed axial runs and replicate

Table 2. Independent variables and their coded levels for CCD.

\begin{tabular}{lcccc}
\hline \multirow{2}{*}{ Variables } & \multirow{2}{*}{ Code } & \multicolumn{4}{c}{ Coded variable level } \\
\cline { 2 - 5 } & & $\mathbf{- 1}$ & $\mathbf{0}$ & $\mathbf{1}$ \\
\hline Disc-blade intercepting angle $\left(^{\circ}\right)$ & $\mathrm{X}_{1}$ & 30 & 90 & 150 \\
Reynolds number $\left(\times 10^{4}\right)$ & $\mathrm{X}_{2}$ & 1.70 & 4.10 & 6.60 \\
Superficial gas velocity $(\mathrm{mm} / \mathrm{s})$ & $\mathrm{X}_{3}$ & 1 & 2 & 3 \\
\hline
\end{tabular}


tests at the centre. $\mathrm{N}$ represents the total number of experiments while " $\mathrm{n}$ " is the number of variables:

$\mathrm{N}=2^{\mathrm{n}}+2 \mathrm{n}+\mathrm{n}_{\mathrm{c}}$

For the two variable sets consisting of "disc-blade intercepting angle, Reynolds number" and "superficial gas velocity, disc-blade intercepting angle", 4 factorial runs, 4 fixed axial runs and 5 replications of centre points were chosen. Replications of centre points are used to predict the experimental standard error of prediction. Hence, the total number of experiments required for each set of experiments was 13. The low and high limits are coded as -1 and +1 , the independent variables were coded to the $(-1,1)$ interval, respectively. The axial points are placed at $( \pm \alpha, 0)$ and $(0, \pm \alpha)$, where the distance of the axial point from centre is $\alpha$. The value of $\alpha$ can be calculated by equation (8).

$\alpha=\left(2^{\mathrm{n}}\right)^{0.25}$

In this study, the value of $\alpha$ was fixed at 1 . Modification of the experimental data was done by a second order polynomial regression model:

$\mathrm{Y}=\beta_{0}+\sum_{\mathrm{i}=1}^{3} \beta_{\mathrm{i}} \mathrm{x}_{\mathrm{i}}+\sum_{\mathrm{i}=1}^{3} \beta_{\mathrm{ii}} \mathrm{x}_{\mathrm{i}}^{2}+\sum_{\mathrm{i}=1}^{2} \sum_{\mathrm{j}=\mathrm{i}+1}^{3} \beta_{\mathrm{ij}} \mathrm{x}_{\mathrm{i}} \mathrm{x}_{\mathrm{j}}$

Design-Expert software (DOE) (version 8.0.10, Stat-Ease, Inc., Minneapolis, USA), was used in this study to perform the statistical analysis. The variance analysis (ANOVA) was applied to verify the significance of the models, factors, coefficients and regression, statistically. The complete design matrices of the experiments performed, together with the results obtained for both power number, $\mathrm{N}_{\mathrm{p}}$ and mass transfer coefficient, $\mathrm{k}_{\mathrm{L}} \mathrm{a}$, are shown in Tables 3 and 4 .

\section{RESULTS AND DISCUSSION}

\section{Power Number}

The standard Rushton turbine design with a discblade intercepting angle of $90^{\circ}$ was used to validate the accuracy of the system. The power number of the Rushton turbine found in this work was 5.47, which is in close agreement with those published in the literature (Bates et al., 1963; Houcine et al., 2000; Nienow et al., 1995; Wu et al., 2001). In the turbulent region with the Reynolds number ranging from $2 \times 10^{4}$ to $6.6 \times 10^{4}$, the power number of all impellers showed insignificant variations with increasing Reynolds number (Figure 3 ). The power numbers were averaged to obtain the impeller's power number (Bujalski et al., 1987). Individual power numbers for each impeller are presented in Figure 4. Changing disc-blade
Table 3. Experimental design matrix and response results for $\mathrm{N}_{\mathrm{p}}$.

\begin{tabular}{ccccc}
\hline Run & Type & $\begin{array}{c}\text { Disc-blade } \\
\text { intercepting } \\
\text { angle, } \mathbf{X}_{\mathbf{1}}\end{array}$ & $\begin{array}{c}\text { Reynolds } \\
\text { number, } \\
\mathbf{X}_{\mathbf{2}}\left(\times \mathbf{1 0}^{-4}\right)\end{array}$ & $\begin{array}{c}\text { Power } \\
\text { number, } \\
\mathbf{Y}_{\mathbf{1}}\end{array}$ \\
\hline 1 & Center & 90 & 4.10 & 5.86 \\
2 & Axial & 150 & 4.10 & 1.19 \\
3 & Factorial & 150 & 1.70 & 0.87 \\
4 & Center & 90 & 4.10 & 5.93 \\
5 & Factorial & 30 & 1.70 & 0.87 \\
6 & Center & 90 & 4.10 & 5.93 \\
7 & Center & 90 & 4.10 & 5.86 \\
8 & Axial & 90 & 6.60 & 5.96 \\
9 & Center & 90 & 4.10 & 5.86 \\
10 & Factorial & 30 & 6.60 & 1.47 \\
11 & Axial & 90 & 1.70 & 3.92 \\
12 & Axial & 30 & 4.10 & 1.32 \\
13 & Factorial & 150 & 6.60 & 1.31 \\
\hline
\end{tabular}

Table 4. Experimental design matrix and response results for $\mathrm{k}_{\mathrm{L}} \mathrm{a}$.

\begin{tabular}{ccccc}
\hline Run & Type & $\begin{array}{c}\text { Disc-blade } \\
\text { Intercepting } \\
\text { angle, } \mathbf{X}_{\mathbf{1}}\end{array}$ & $\begin{array}{c}\text { Superficial } \\
\text { gas velocity, } \\
\mathbf{X}_{\mathbf{3}}\end{array}$ & $\begin{array}{c}\mathbf{k}_{\mathbf{L}} \mathbf{a}\left(\mathbf{s}^{\mathbf{- 1}}\right) \\
\mathbf{Y}_{\mathbf{2}}\end{array}$ \\
\hline 1 & Factorial & 150 & 3 & 0.0073 \\
2 & Center & 90 & 2 & 0.0106 \\
3 & Center & 90 & 2 & 0.0114 \\
4 & Factorial & 30 & 1 & 0.0042 \\
5 & Factorial & 30 & 3 & 0.0087 \\
6 & Axial & 30 & 2 & 0.0065 \\
7 & Factorial & 150 & 1 & 0.0050 \\
8 & Center & 90 & 2 & 0.0115 \\
9 & Center & 90 & 2 & 0.0112 \\
10 & Center & 90 & 2 & 0.0122 \\
11 & Axial & 90 & 3 & 0.0141 \\
12 & Axial & 150 & 2 & 0.0065 \\
13 & Axial & 90 & 1 & 0.0076 \\
\hline
\end{tabular}

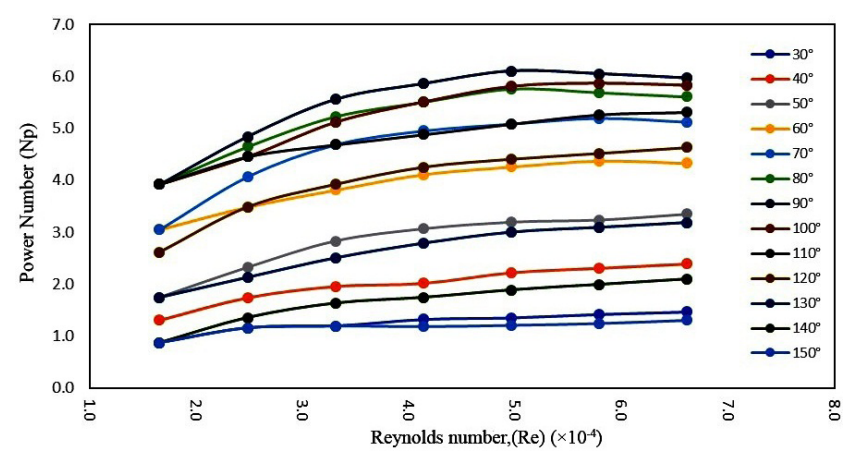

Figure 3. Power number versus Reynolds number for all impellers used.

intercepting angle was found to have a definite effect on the impeller's power number. The power number increased linearly with increasing blade angle from $30^{\circ}$ to $90^{\circ}$ (right angle). Further increment beyond $90^{\circ}$ causes a reduction in the power number of impellers. In comparison with the Rushton turbine, the $30^{\circ}$ impeller had a relatively lower power number by $77 \%$, the $60^{\circ}$ impeller had $28 \%$ lower power number, the $120^{\circ}$ impeller had a lower power number of $27 \%$ and the 


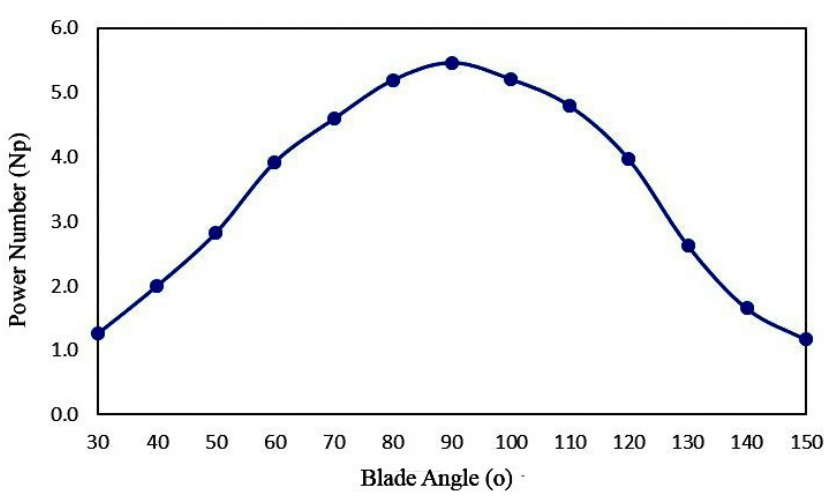

Figure 4. Power number of each impeller.

$150^{\circ}$ impeller had a lower power number by $79 \%$. The power number reduction became less profound while approaching the right angle. Among all the studied impellers, the $150^{\circ}$ impeller showed the lowest power number of 1.17. The results proved that changing the disc-blade intercepting angle could reduce the power consumption of the conventional Rushton design. The power dissipation of an impeller is determined by the size and rotation of the trailing vortices created behind the blade (Van't Riet and Smith, 1975; Vasconcelos et al., 2000). Therefore, the power number reduction could be associated with vortex trail reduction and less dominant flow separation formation when the blade is angled forward or backward. Therefore, lower power is required compared with the Rushton turbine because of considerably higher blade contact area for the Rushton turbine.

\section{Just Suspended Speed, $\mathbf{N}_{\mathrm{Js}}$}

Figure 5 presents the values of just suspended speed, $\mathrm{N}_{\mathrm{js}}$ for impellers with disc-blade intercepting angle varying from $30^{\circ}$ to $150^{\circ}$ in $5 \mathrm{wt} \%$ solids suspension. The measured $\mathrm{N}_{\mathrm{js}}$ for the $90^{\circ}$ Rushton turbine in this work was lower by $15 \%$ than the value predicted by Zwietering's correlation (Zwietering, 1958). The discrepancy could be attributed to the smaller vessel size used in this experiment (Rewatkar and Joshi, 1991). The minimum agitation speed for the just suspension condition is closely associated with the

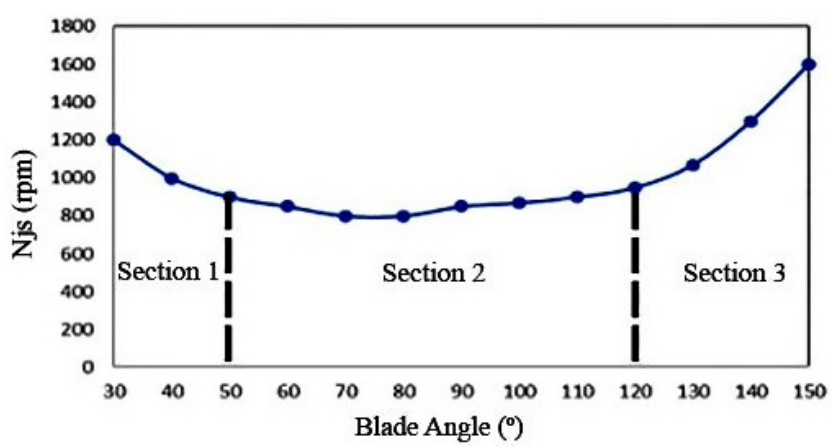

Figure 5. Variation of $\mathrm{N}_{\mathrm{js}}$ with disc-blade intercepting angle. hydrodynamics of the flow generated by the impeller (Gray, 1987). In this case, it was observed that all the impellers generate a typical radial flow pattern like the standard Rushton turbine, where the discharged flow from the impeller hit the tank walls and slid down along the walls and turned at the corners towards the centre of the tank base. The solid particles were driven towards the centre of the vessel bottom and are the last to be suspended.

Figure 5 presents the Variation of $\mathrm{N}_{\mathrm{js}}$ with discblade intercepting angle. The second section in the graph shows that the suspension was achieved at a generally lower speed for angles between $50^{\circ}$ and $120^{\circ}$. This phenomenon could be rationalized such that the impellers with disc-blade intercepting angles in Section 2 generated flow with higher turbulent kinetic energy in the vessel that was sufficient to lift the particles off the bottom. Whereas for the impellers out of this range, their vortex generation was so mild that the solid particles require much higher speed to gain enough energy to escape from the tank bottom. In fact, impellers in the second section with low justsuspended speed characteristic are advantageous for mixing of sensitive products and applications that require lower wear-and-tear and low aeration.

In terms of energy efficiency, the specific power, $\varepsilon_{\text {is }}(\mathrm{W} / \mathrm{kg})$ required at the just suspended condition is a useful measurement for off-bottom solid suspensions and is defined through the following expression:

$\varepsilon_{\mathrm{js}}=\mathrm{P}_{\mathrm{js}} / \mathrm{M}_{\mathrm{s}}$

The $\varepsilon_{\mathrm{j} s}$ values of the impellers are presented in Figure 6 . The Figure could generally be divided into three segments based on the power consumption, which were the first section $\left(30^{\circ}\right.$ to $\left.80^{\circ}\right)$, second section $\left(90^{\circ}\right.$ to $\left.120^{\circ}\right)$ and third section $\left(130^{\circ}\right.$ to $\left.150^{\circ}\right)$. The impellers described in the Section 1 were more energy efficient impellers because they consumed lower power to achieve suspension compared to the others. When the blades are leaned backwards, they create a flatter contact surface with the liquid, thus

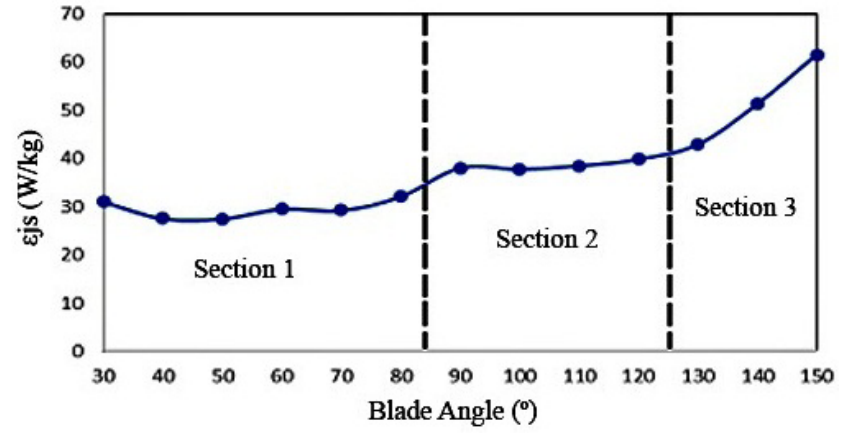

Figure 6. Specific power, $\varepsilon_{\text {is }}$ values for impellers of various disc-blade intercepting angles. 
lesser flow resistance and less energy was lost as eddies.

\section{Mass Transfer Coefficient, $k_{\mathrm{L}}$ a}

The effect of gas flow rate was investigated at constant impeller speed (6.67 rps) and impeller angle $30^{\circ}, 90^{\circ}$ and $150^{\circ}$. The results in Figure 7 indicated that gas-liquid mass transfer coefficient was affected by the rate of air introduced into the system. Mass transfer was increased when the superficial gas velocity was increased from $0.001 \mathrm{~m} / \mathrm{s}$ to $0.003 \mathrm{~m} / \mathrm{s}$ for all the three tested impellers. This was because, when the air flow rate increases, more generated air bubbles raises the available interfacial area, which causes higher mass transfer (Al-Balushi et al., 2016). This result is supported by other authors who found that gas flow rate is in fact a significant parameter affecting mass transfer efficiency (Van't Riet, 1979; Vasconcelos et al., 2000). Furthermore, the effect of disc-blade intercepting angle is studied under conditions of constant superficial gas velocity and impeller speed (6.67 rps).

The highest mass transfer coefficient is shown by the $90^{\circ}$ impeller when compared to $30^{\circ}$ and $150^{\circ}$, as shown in Figure 8. This could be due to the lower shear stress produced by the $30^{\circ}$ and $150^{\circ}$ angled-blades and

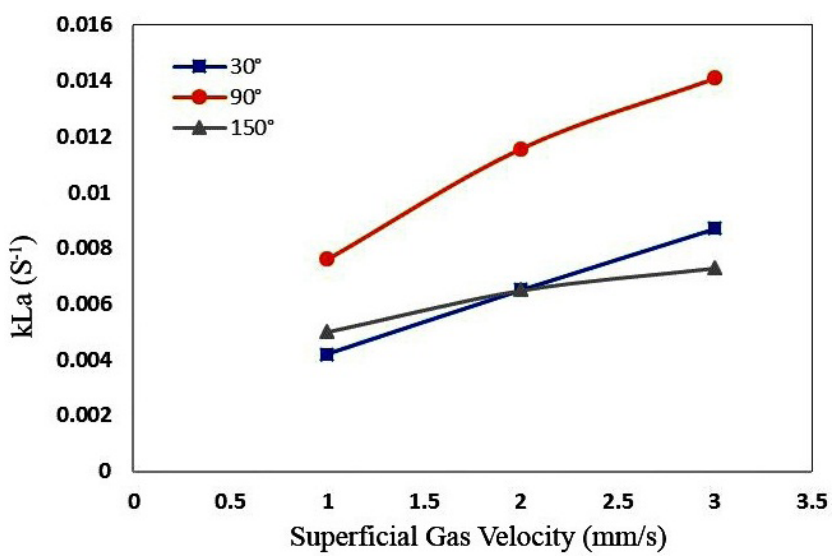

Figure 7. Variation of $\mathrm{k}_{\mathrm{r}} \mathrm{a}$ of $30^{\circ}, 90^{\circ}$ and $150^{\circ}$ impellers at different superficial gas velocities

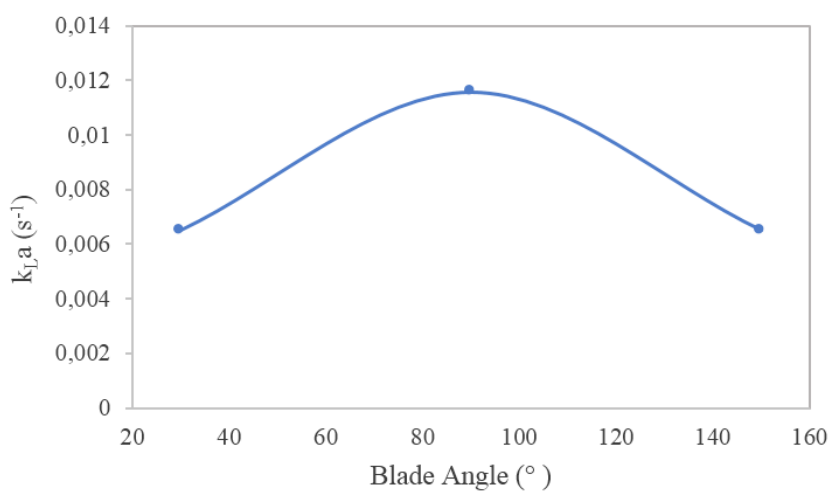

Figure 8. Variation of $\mathrm{k}_{\mathrm{L}}$ a values with impeller's discblade intercepting angles. thus weaker gas dispersion ability (Chen and Chen). The $90^{\circ}$ Rushton has relatively larger swept volume area and creates greater shear stress with better gas dispersing ability. This Figure also suggests that an impeller at the central region would have better mass transfer performance, and thus impeller design should prefer disc-blade intercepting angles in the central region and avoid the angles at two ends.

\section{Variables Statistical Analysis \\ Power number}

A quadratic model was suggested by the software and fitted to the power numbers through regression analysis. Figure 9(a) shows the prediction model versus the actual experimental data.

In term of coded factors, the interaction between the experimental parameters, power number, $\mathrm{Y}_{1}$ and disc-blade intercepting angle, $\mathrm{X}_{1}$ could be expressed in the following empirical relationship:

$Y_{1}=-1.59 \times 10^{8}-4.24 X_{1}^{2}$

The results of analysis of variance (ANOVA) for the response surface quadratic model for $\mathrm{N}_{p}$ are presented in Table 5. The suitability of the statistical model was evaluated by the $\mathrm{R}^{2}$ value,

A.

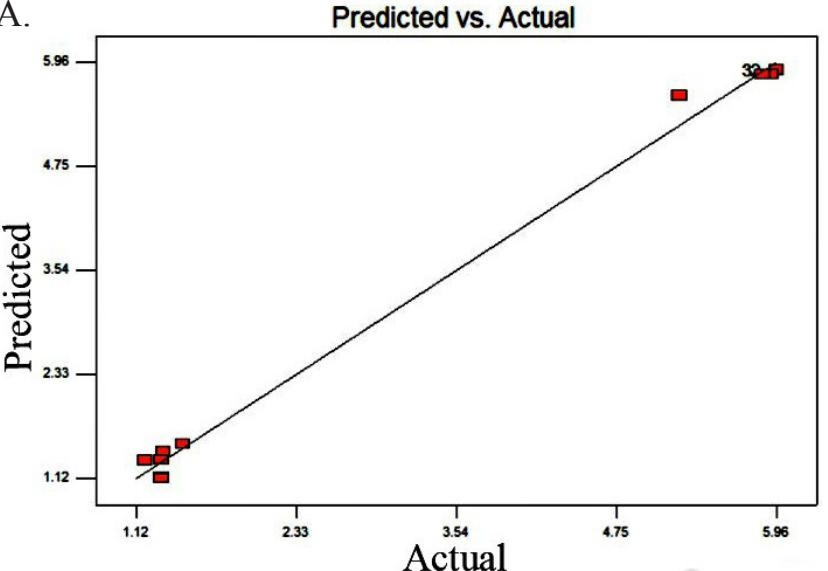

B.

Predicted vs. Actual

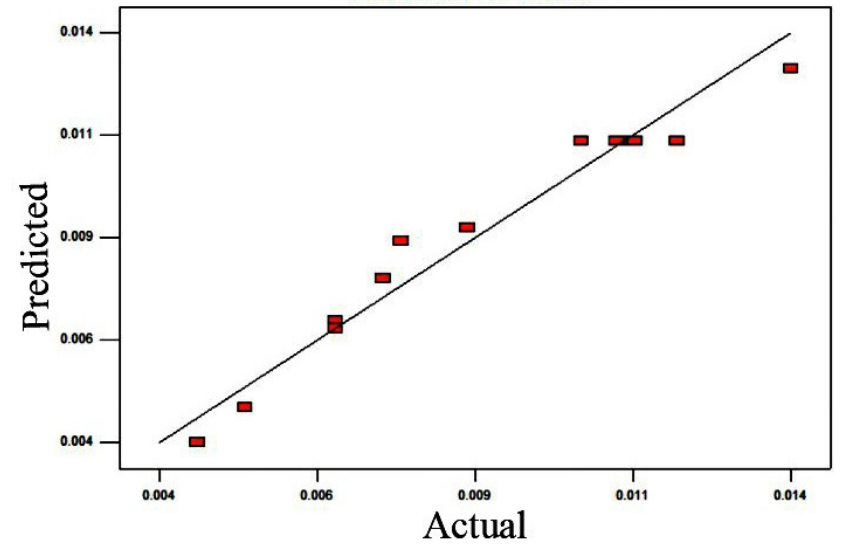

Figure 9. Predicted vs. actual value for (a) power number and (b) mass transfer coefficient. 
and its statistical significance was checked by Fisher's F-test. The F-value of the model was 74.60 with low probability value of less than 0.0001 , which implies that the model is significant. $\mathrm{R}$ squared equal to 0.9816 justifies that the model is a satisfactory fit to the experimental data. For each term in the model equation, a probability value of "Prob $>F$ " less than 0.05 indicates that it is a significant factor (Ahnazarova et al., 1982; Khuri

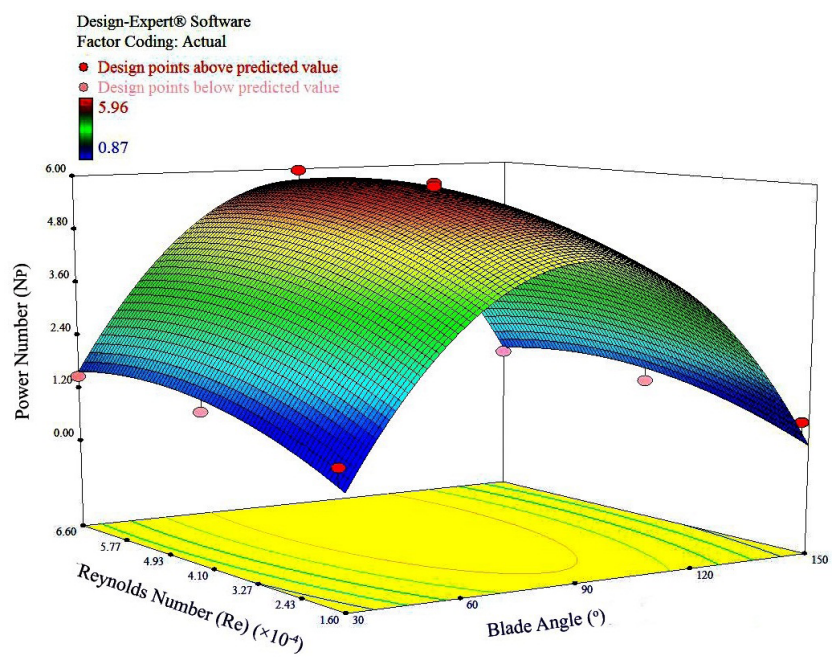

Figure 10. Comparison of $\mathrm{N}_{\mathrm{p}}$ values with various discblade intercepting angles. and Cornell, 1996). In this case, the second order of the disc-blade intercepting angle, $\mathrm{X}_{1}^{2}$ demonstrated a high significance with $\mathrm{p}$-value $<0.0001$. Figure 10 illustrates the interaction effects of the input factors on the response variable.

\section{Mass transfer coefficient}

A quadratic regression model was proposed by the experimental design software for the effect of superficial gas velocity, $X_{3}$ and disc-blade intercepting angle, $X_{1}$ on mass transfer coefficient, $Y_{2}$. Figure 9(b) shows the prediction model versus the actual experimental data. The interaction between parameters, mass transfer coefficient, $Y_{2}$, superficial gas velocity, $\mathrm{X}_{3}$ and discblade intercepting angle, $X_{1}$ can be expressed in coded factors as:

$$
\mathrm{Y}_{2}=0.011+0.002217 \mathrm{X}_{3}-0.004721 \mathrm{X}_{1}^{2}
$$

The results of analysis of variance (ANOVA) are given in Table 6. The F-value of 32.46 and $\mathrm{R}^{2}$ of 0.9587 denotes that the model is significant. Among the model terms, the first order of superficial gas velocity, $\mathrm{X}_{3}$ and second order of disc-blade intercepting angle, $\mathrm{X}_{1}^{2}$ were of significant model factors. The effect of blade angle and superficial gas velocity on mass transfer coefficient is presented in Figure 11.

Table 5. Analysis of variance (ANOVA) for the response surface quadratic model for $\mathrm{N}_{\mathrm{p}}$.

\begin{tabular}{ccccccc}
\hline Source & $\begin{array}{c}\text { Sum } \\
\text { of squares }\end{array}$ & $\begin{array}{c}\text { Degree } \\
\text { of freedom }\end{array}$ & $\begin{array}{c}\text { Mean } \\
\text { of square }\end{array}$ & F-value & $\begin{array}{c}\text { p-Value } \\
\text { (Prob>F) }\end{array}$ & Remarks \\
\hline Model & 66.29 & 5 & 13.26 & 74.60 & $<0.0001$ & Significant \\
$\mathrm{X}_{1}$ & $6.346 \times 10^{-3}$ & 1 & $6.346 \times 10$ & 0.036 & 0.8555 & \\
$\mathrm{X}_{2}$ & 0.87 & 1 & 0.87 & 4.89 & 0.0626 & \\
$\mathrm{X}_{1}{ }^{2}$ & 49.55 & 1 & 49.55 & 278.82 & $<0.0001$ \\
$\mathrm{X}_{2}{ }^{2}$ & 0.87 & 1 & 0.87 & 4.89 & 0.0626 \\
$\mathrm{X}_{1} \mathrm{X}_{2}$ & $6.345 \times 10^{-3}$ & 1 & $6.345 \times 10^{-3}$ & 0.036 & 0.8555 \\
Residual & 1.24 & 7 & 0.18 & & & $<0.001$ \\
Lack of fit & 1.24 & 3 & 0.41 & 280.76 & & \\
Pure error & $5.88 \times 10^{-3}$ & 4 & $1.47 \times 10^{-3}$ & & & \\
Cor total & 67.53 & 12 & & & & \\
R-squared & 0.9816 & & & & &
\end{tabular}

Table 6. Analysis of variance (ANOVA) for the response surface quadratic model for $\mathrm{k}_{\mathrm{L}} \mathrm{a}$.

\begin{tabular}{ccccccc}
\hline Source & $\begin{array}{c}\text { Sum } \\
\text { of squares }\end{array}$ & $\begin{array}{c}\text { Degree } \\
\text { of freedom }\end{array}$ & $\begin{array}{c}\text { Mean } \\
\text { of square }\end{array}$ & F-value & $\begin{array}{c}\text { p-Value } \\
\text { Prob>F }\end{array}$ & Remarks \\
\hline Model & $1.075 \times 10^{-4}$ & 5 & $2.150 \times 10^{-5}$ & 32.46 & 0.0001 & Significant \\
$\mathrm{X}_{3}$ & $2.948 \times 10^{-5}$ & 1 & $2.948 \times 10^{-5}$ & 44.51 & 0.0003 & \\
$\mathrm{X}_{1}$ & $6.000 \times 10^{-8}$ & 1 & $6.000 \times 10^{-8}$ & 0.091 & 0.7722 & \\
$\mathrm{X}_{3}{ }^{2}$ & $3.795 \times 10^{-7}$ & 1 & $3.795 \times 10^{-7}$ & 0.57 & 0.4738 \\
$\mathrm{X}_{1}{ }^{2}$ & $6.155 \times 10^{-5}$ & 1 & $6.155 \times 10^{-5}$ & 92.93 & $<0.0001$ \\
$\mathrm{X}_{3} \mathrm{X}_{1}$ & $1.210 \times 10^{-6}$ & 1 & $1.210 \times 10^{-6}$ & 1.83 & 0.2185 \\
Residual & $4.636 \times 10^{-6}$ & 7 & $6.623 \times 10^{-7}$ & & & \\
Lack of fit & $3.308 \times 10^{-6}$ & 3 & $1.103 \times 10^{-6}$ & 3.32 & & \\
Pure error & $1.328 \times 10^{-6}$ & 4 & $3.320 \times 10^{-7}$ & & & \\
Cor total & $1.121 \times 10^{-6}$ & 12 & & & & \\
R-squared & 0.9587 & & & & &
\end{tabular}




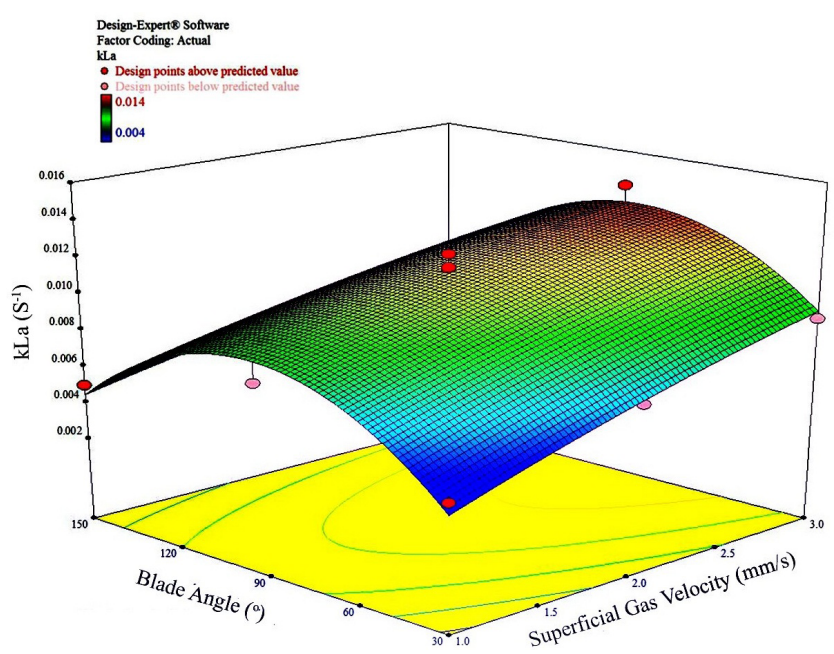

Figure 11. Comparison of $\mathrm{k}_{\mathrm{L}}$ a values with various disc-blade intercepting angles.

\section{CONCLUSION}

The effects of disc-blade intercepting angle on power, just suspended speed and mass transfer coefficient were investigated. Response Surface Methodology (RSM) was used to determine the relationship between interacting parameters and model development for the power number and 'mass transfer coefficient. The results indicated a significant relation between the disc-blade intercepting angle and impeller power number. Power number was found to increase with disc-blade intercepting angle from $30^{\circ}$ to $90^{\circ}$ while reduction was observed beyond $90^{\circ}$. Among all tested impellers, $90^{\circ}$ gave the highest $\mathrm{N}_{\mathrm{p}}$ of 5.47 and impeller with an angle of $150^{\circ}$ gave the lowest $\mathrm{N}_{\mathrm{p}}$ of 1.17. For the solid suspension, impellers with disc-blade intercepting angle between $50^{\circ}$ and $120^{\circ}$ generally required lower speed to achieve suspension in comparison with the others. Among them, the impellers with an angle from $50^{\circ}$ to $80^{\circ}$ were also superior in terms of energy efficiency $\left(\mathcal{E}_{\mathrm{js}}\right)$ at suspension. For mass transfer performance, the highest mass transfer coefficient was shown by the conventional $90^{\circ}$ Rushton design, while much poor mass transfers were obtained at $30^{\circ}$ and $150^{\circ}$. Therefore, it was recommended that impeller design should adhere to the disc-blade intercepting angles in the middle range, e.g. $60^{\circ}$ to $120^{\circ}$.

\section{ACKNOWLEDGEMENTS}

The authors are grateful to the University Malaya Research Grant (UMRG) - Frontier Science (AFR) RG384-17AFR and Postgraduate Research Fund from University of Malaya for financially supporting this research. Special thanks to the Department of Chemical Engineering, Faculty of Engineering, University of Malaya for the resources and facilities provided.

\section{NOMENCLATURE}

Bw Baffle width (m)

$\mathrm{C} \quad$ Impeller off bottom clearance (m)

CCD Central composite design

$\mathrm{Cs} \quad$ Sparger clearance $(\mathrm{m})$

C* Saturated dissolved oxygen concentration $(\mathrm{mg} / \mathrm{l})$

$\mathrm{C}_{0} \quad$ Initial oxygen concentration $(\mathrm{mg} / \mathrm{l})$

$\mathrm{C}_{\mathrm{t}} \quad$ Dissolved oxygen concentration at time $\mathrm{t}$ $(\mathrm{mg} / \mathrm{l})$

D Impeller diameter $(\mathrm{m})$

$\mathrm{D}_{\mathrm{H}} \quad$ Sparger hole diameter $(\mathrm{mm})$

Ds $\quad$ Sparger diameter $(\mathrm{m})$

dp Particle size or particle diameter (m)

g Acceleration due to gravity $\left(\mathrm{m} / \mathrm{s}^{2}\right)$

$\mathrm{H} \quad$ Liquid height (m)

$\mathrm{k}_{\mathrm{L}} \mathrm{a} \quad$ Volumetric mass transfer coefficient at the gas-liquid interface $\left(\mathrm{s}^{-1}\right)$

$\mathrm{M}_{\mathrm{s}} \quad$ Mass of suspended solids $(\mathrm{kg})$

n Number of variables

$\mathrm{N} \quad$ Impeller rotational speed (rps)

$\mathrm{N}_{\text {is }} \quad$ Just suspended speed (rps)

$\mathrm{N}_{\mathrm{p}}^{\mathrm{js}} \quad$ Power number (dimensionless)

$\mathrm{P}^{\mathrm{p}} \quad$ Power consumption (W)

PBT Pitched blade turbine

$\mathrm{P}_{\mathrm{js}} \quad$ Power consumption at just-suspended speed (W)

Re Reynolds number (dimensionless)

$\mathrm{R}_{\mathrm{ID}} \quad$ Sparger inner diameter (m)

$\mathrm{R}_{\mathrm{OD}} \quad$ Sparger outer diameter (m)

RSM Response surface methodology

RT Rushton turbine

$\mathrm{S} \quad$ Zwietering S constant (dimensionless)

$\mathrm{t} \quad$ Time $(\mathrm{s})$

T Tank diameter (m)

Us Superficial gas velocity $(\mathrm{m} / \mathrm{s})$

$\mathrm{V} \quad$ Operating volume $\left(\mathrm{m}^{3}\right)$

wt $\%$ Weight percent

W Impeller blade width (m)

$\mathrm{X} \%$ concentration of solids (mass of solids mass of liquid)

\section{Greek Symbols}

$\varepsilon_{\mathrm{js}} \quad$ Specific power per unit solids mass at just suspended condition $(\mathrm{W} / \mathrm{kg})$

$\rho_{\mathrm{L}} \quad$ Liquid density $\left(\mathrm{kg} / \mathrm{m}^{3}\right)$

$\rho_{\mathrm{S}} \quad$ Solid density $\left(\mathrm{kg} / \mathrm{m}^{3}\right)$

$\tau \quad$ Torque $\left(\mathrm{kg} \mathrm{m}^{2} / \mathrm{s}^{2}\right)$

$\mu \quad$ Dynamic viscosity of liquid $(\mathrm{kg} / \mathrm{m} \mathrm{s})$

$v \quad$ Kinematic viscosity of liquid $\left(\mathrm{m}^{2} / \mathrm{s}\right)$

$\alpha \quad$ Distance of axial point from the center point

$\beta_{0} \quad$ Constant coefficient

$\beta_{i} \quad$ Linear effect

$\beta_{\mathrm{ii}} \quad$ Quadratic coefficient 
$\beta_{\mathrm{ij}} \quad$ Interaction coefficients

$\mathrm{x}_{\mathrm{i}}, \mathrm{x}_{\mathrm{j}} \quad$ Coded values

\section{REFERENCES}

Afshar Ghotli, R., Abdul Aziz, A.R., Ibrahim, S., Baroutian, S., Arami-Niya, A. Study of various curvedblade impeller geometries on power consumption in stirred vessel using response surface methodology. J. Taiwan Inst.Chem. Eng., 44, 192-201 (2013). https:// doi.org/10.1016/j.jtice.2012.10.010

Afshar Ghotli, R., Abdul Raman, A.A., Ibrahim, $\mathrm{S}$. The effect of various designs of six-curved blade impellers on reaction rate analysis in liquid-liquid mixing vessel. Measurement., 91, 440-450 (2016). https://doi.org/10.1016/j. measurement.2016.04.044

Ahnazarova, S.L., Kafarov, V.V., Mackovskij, V.M., Rep'ev, A.P. Experiment optimization in chemistry and chemical engineering. Mir Publishers (1982).

Al-Balushi, L., Al-Qasimy, M., Talebi, S., Al-Haddabi, S., Al-Maawali, S., Al-Dalla, A. Study on the Hydrodynamics of Stirred Vessels. Int. J. Sci. Eng. Res., 7, 411-416 (2016).

Arjunwadkar, S.J., Sarvanan, K., Kulkarni, P.R., Pandit, A.B. Gas-liquid mass transfer in dual impeller bioreactor. Biochem. Eng. J., 1, 99-106 (1998). https://doi.org/10.1016/S1385-8947(97)00083-1

Asgharzadehahmadi, S., Davoody, M., Ghotli, R.A., Raman, A.A.A., Parthasarathy, R. Effect of ultrasonic irradiations on gas-liquid mass transfer coefficient (kLa); Experiments and modelling. Measurement., 79, 119-129 (2016). https://doi. org/10.1016/j.measurement.2015.10.034

Bates, R.L., Fondy, P.L., Corpstein, R.R. Examination of Some Geometric Parameters of Impeller Power. Ind. Eng. Chem. Proc. Des. Dev., 2, 310-314 (1963). https://doi.org/10.1021/i260008a011

Bujalski, W., Nienow, A., Chatwin, S., Cooke, M. The dependency on scale of power numbers of Rushton disc turbines. Chem. Eng. Sci., 42, 317-326 (1987). https://doi.org/10.1016/0009-2509(87)85061-3

Chapple, D., Kresta, S.M., Wall, A., Afacan, A. The Effect of Impeller and Tank Geometry on Power Number for a Pitched Blade Turbine. Chem. Eng. Res. Des., 80, 364-372 (2002). https://doi. org/10.1205/026387602317446407

Chen, Z.D., Chen, J. Comparison of mass transfer performance for various single and twin impellers. Chem. Eng. Res. Des., 77, 104-109 (1999). https:// doi.org/10.1205/026387699525972

Chen, Z.D., Chen, J.J.J. A study of agitated gas-liquid reactors with concave blade impellers, in: Gupta, B.S., Ibrahim, S. (Eds.), Mixing and crystalization. Kluwer Academic Publishers, Malaysia, pp. 43-56 (2000). https://doi.org/10.1007/978-94-017-2290-2_4
Cooke, M., Heggs, P.J. Advantages of the hollow (concave) turbine for multi-phase agitation under intense operating conditions. Chem. Eng. Sci., 60, 5529-5543 (2005). https://doi.org/10.1016/j. ces.2005.05.018

Forrester, S.E., Rielly, C.D., Carpenter, K.J. Gasinducing impeller design and performance characteristics. Chem. Eng. Sci., 53, 603-615(1998). https://doi.org/10.1016/S0009-2509(97)00352-7

Gray, D.J. Impeller clearance effect on off bottom particle suspension in agitated vessels. Chem. Eng. Commun., 61, 151-158 (1987). https://doi. org/10.1080/00986448708912035

Houcine, I., Plasari, E., David, R. Effects of the stirred tank's design on power consumption and mixing time in liquid phase. Chem. Eng. Technol., 23, 605-613 (2000). https://doi.org/10.1002/1521$4125(200007) 23: 7 \% 3$ C 605 : : A I D CEAT605\%3E3.0.CO;2-0

Jahoda, M., Mostek, M., Kukuková, A., Machon, V. CFD Modelling of Liquid Homogenization in Stirred Tanks with One and Two Impellers Using Large Eddy Simulation. Chem. Eng. Res. Des., 85, 616-625 (2007). https://doi.org/10.1205/cherd06183

Jeong, G.-T., Yang, H.-S., Park, D.-H. Optimization of transesterification of animal fat ester using response surface methodology. Bioresour. Technol., 100, 25-30 (2009). https://doi.org/10.1016/j. biortech.2008.05.011

Jirout, T., Rieger, F. Impeller design for mixing of suspensions. Chem. Eng. Res. Des., 89, 1144-1151 (2011). https://doi.org/10.1016/j. cherd.2010.12.005

Kapic, A., Heindel, T. Correlating gas-liquid mass transfer in a stirred-tank reactor. Chem. Eng. Res. Des., 84, 239-245(2006). https://doi.org/10.1205/ cherd.05117

Karcz, J., Major, M. An Effect of a Baffle Length on the Power Consumption in an Agitated Vessel. Chem. Eng. Proces., 37, 249-256 (1998). https:// doi.org/10.1016/S0255-2701(98)00033-6

Kasat, G.R., Pandit, A.B. Review on Mixing Characteristics in Solid-Liquid and Solid-Liquid-Gas Reactor Vessels. Can. J. Chem. Eng., 83, 618-643 (2005). https://doi.org/10.1002/cjce.5450830403

Khare, A.S., Niranjan, K. An experimental investigation into the effect of impeller design on gas hold-up in a highly viscous Newtonian liquid. Chem. Eng. Sci., 54, 1093-1100 (1999). https://doi. org/10.1016/S0009-2509(98)00479-5

Khuri, A.I., Cornell, J.A. Response surfaces: designs and analyses. CRC press (1996).

Kumaresan, T., Joshi, J.B. Effect of impeller design on the flow pattern and mixing in stirred tanks. Chem. Eng. J., 115, 173-193 (2006). https://doi. org/10.1016/j.cej.2005.10.002 
Kumaresan, T., Nere, N.K., Joshi, J.B. Effect of Internals on the Flow Pattern and Mixing in Stirred Tanks. Ind. Eng. Chem. Res., 44, 9951-9961(2005). https://doi.org/10.1021/ie0503848

Mhetras, M.B., Pandit, A.B., Joshi, J.B. Effect of agitator design on hydrodynamics and power consumption in mechanically agitated gas-liquid reactors, Eighth European Conference on Mixing, UK, pp. 375-382 (1994).

Nienow, A., Kendall, A., Moore, I., Ozcan-Taskin, G., Badham, R. The characteristics of aerated 12-and 18-blade Rushton turbines at transitional Reynolds numbers. Chem. Eng. Sci., 50, 593-599 (1995). https://doi.org/10.1016/0009-2509(94)00250-U

Nienow, A.W. Suspension of solid particles in turbine agitated baffled vessels. Chem. Eng. Sci., 23, 1453-1459 (1968). https://doi.org/10.1016/00092509(68)89055-4

Nienow, A.W. On impeller circulation and mixing effectiveness in the turbulent flow regime. Chem. Eng. Sci., 52, 2557-2565 (1997). https://doi. org/10.1016/S0009-2509(97)00072-9

Nienow, A.W., Miles, D. Impeller power numbers in closed vessels. Ind. Eng. Chem. Proc. Des. Dev., 10, 41-43 (1971). https://doi.org/10.1021/i260037a007

Pacek, A.W., Chamsart, S., Nienow, A.W., Bakker, A. The influence of impeller type on mean drop size and drop size distribution in an agitated vessel. Chem. Eng. Sci., 54, 4211-4222 (1999). https://doi. org/10.1016/S0009-2509(99)00156-6

Patwardhan, A.W., Joshi, J.B. Relation between Flow Pattern and Blending in Stirred Tanks. Ind. Eng. Chem. Res., 38, 3131-3143(1999). https://doi. org/10.1021/ie980772s

Rewatkar, V., Deshpande, A., Pandit, A., Joshi, J. Gas hold $\square$ up behavior of mechanically agitated gas $\square$ liquid reactors using pitched blade downflow turbines. Can. J. Chem. Eng., 71, 226-237 (1993). https://doi.org/10.1002/cjce.5450710209

Rewatkar, V.B., Joshi, J.B. Critical impeller speed for solid suspension in mechanically agitated threephase reactors. 2. Mathematical model. Ind. Eng. Chem. Res., 30, 1784-1791 (1991). https://doi. org/10.1021/ie00056a014

Rewatkar, V.B., Rao, K.R., Joshi, J.B. Critical impeller speed for solid suspension in mechanically agitated three-phase reactors. 1. Experimental part. Ind. Eng. Chem. Res., 30, 1770-1784 (1991). https:// doi.org/10.1021/ie00056a013

Rewatkar, V.B., Rao, K.S.M.S.R., Joshi, J.B. Power consumption in mechanically agitated contactors using pitched bladed turbine impellers. Chem. Eng. Commun., 88, 69-90 (1990). https://doi. org/10.1080/00986449008940548

Rushton, J., Costich, E., Everett, H. Power characteristics of mixing impellers. 2. Chem. Eng. Prog., 46, 467-476 (1950).

Rutherford, K., Mahmoudi, S., Lee, K., Yianneskis, M. The influence of Rushton impeller blade and disk thickness on the mixing characteristics of stirred vessels. Chem. Eng. Res. Des., 74, 369-378 (1996).

Schaepe, S., Kuprijanov, A., Sieblist, C., Jenzsch, M., Simutis, R., Lübbert, A., $\mathrm{k}_{\mathrm{L}} \mathrm{a}$ of stirred tank bioreactors revisited. J. Biotechnol., 168, 576-583 (2013). https://doi.org/10.1016/j. jbiotec.2013.08.032

Suhaili, N., Mohamed, M.S., Mohamad, R., Ariff, A.B. Gas-liquid mass transfer performance of dual impeller system employing Rushtons, concavebladed disc (CD-6) turbines and their combination in stirred tank bioreactor. J. Appl. Sci. Res., 6, 234244 (2010).

Sutudehnezhad, N., Zadghaffari, R. CFD Analysis and Design Optimization in a Curved Blade Impeller. Int. J. Chem. Reactor Eng., 15, 137-150 (2017). https://doi.org/10.1515/ijcre-2016-0119

Van't Riet, K., Review of Measuring Methods and Results in Nonviscous Gas-Liquid Mass Transfer in Stirred Vessels. Ind. Eng. Chem. Proc. Des. Dev., 18, 357-364 (1979). https://doi.org/10.1021/ i260071a001

Van't Riet, K., Smith, J.M. The trailing vortex system produced by Rushton turbine agitators. Chem. Eng. Sci., 30, 1093-1105 (1975). https://doi. org/10.1016/0009-2509(75)87012-6

Vasconcelos, J.M.T., Orvalho, S.C.P., Rodrigues, A.M.A.F., Alves, S.S. Effect of Blade Shape on the Performance of Six-Bladed Disk Turbine Impellers. Ind. Eng. Chem. Res., 39, 203-213 (1999). https:// doi.org/10.1021/ie9904145

Warmoeskerken, Smith, J.M. The Hollow Blade Agitator for Dispersion and Mass Transfer. Chem. Eng. Res. Des., 67, 193-198 (1989).

Wu, J., Zhu, Y., Pullum, L. Impeller Geometry Effect on Velocity and Solids Suspension. Chem. Eng. Res. Des., 79, 989-997 (2001). https://doi. org/10.1205/02638760152721857

Zlokarnik, M. Stirring: Theory and practice. John Wiley \& Sons (2008).

Zwietering, T.N. Suspending of solid particles in liquid by agitators. Chem. Eng. Sci., 8, 244-253 (1958). https://doi.org/10.1016/0009-2509(58)85031-9 
